\title{
Comparison and Quantification of the Development of Phenolic Compounds during the Aging of Cachaça in Oak (Quercus sp) and Amburana (Amburana cearensis) Barrels
}

\author{
Wilder D. Santiago ${ }^{1}$, Maria das G. Cardoso ${ }^{1^{*}}$, Juliana de A. Santiago ${ }^{1}$, Marcos S. Gomes ${ }^{1}$, \\ Leonardo M. A. Rodrigues' ${ }^{2}$, Rafaela M. Brandão', Rodolfo R. Cardoso', Gabriel B. d'Avila², \\ Bruno L. da Silva1, Alex R. S. Caetano ${ }^{1}$ \\ ${ }^{1}$ Department of Chemistry, Federal University of Lavras, Lavras, Brazil \\ ${ }^{2}$ Department of Food Science, Federal University of Lavras, Lavras, Brazil \\ Email: ${ }^{\text {mcardoso@dqi.ufla.br }}$
}

Received 22 August 2014; revised 22 September 2014; accepted 5 October 2014

Copyright (C) 2014 by authors and Scientific Research Publishing Inc.

This work is licensed under the Creative Commons Attribution International License (CC BY).

http://creativecommons.org/licenses/by/4.0/

(c) (i)

\begin{abstract}
Aging is a stage of the cachaça production process in which several chemical reactions occur between compounds extracted from the wood and other compounds present on the beverage. In an attempt to establish a profile regarding the chemical characterization of aged cachaças, phenolic compounds have been studied because of the specific characteristics of each wood species and their known antioxidant properties. This work sought to assess and compare the development of 12 phenolic compounds in cachaças aged in oak (Quercus sp) and amburana (Amburana cearenses) barrels during a period of 12 months. There was a progressive increase in the concentration of phenolic compounds in the beverage for both of the types of wood. The principal compounds encountered in the cachaça aged in oak barrels were gallic acid, syringaldehyde and syringic acid, while vanillic acid, syringaldehyde, sinapic acid and gallic acid were isolated from that aged in amburana barrels.
\end{abstract}

\section{Keywords}

Beverage, Aging, Phenolic Compounds, Liquid Chromatography

\footnotetext{
${ }^{*}$ Corresponding author.
} 


\section{Introduction}

Aging of alcoholic beverages is a common practice among producers that try to increase the value to their products, making them more competitive in the market [1]. Aging is responsible for improving organoleptic characteristics of cachaça, making its flavor more pleasant and mild. Some substances from the wood are incorporated into the beverage during aging [2]. In Brazil, most of the cachaça producers are small-scale producers, and a great variety of wood species may be used for aging [3].

Although oak (Quercus sp) is the wood traditionally used for aging alcoholic beverages, several other types of native Brazilian wood species have been employed in the manufacture of barrels for aging cachaça, such as peanut (Plerogyne nitens), amburana (Amburana cearensis), cedar (Cedrela fissilis), jatobá (Hymenaeae carbouril), ipê (Tabebuia sp), freijó (Cordia goeldiana), garapa (Apuleia leiocarpa), balm (Myroxylon peruiferum), yellow mahogany (Plathynemia foliosa) and jequitibá (Carinian legalis) [4]. This practice has developed because of the high cost of oak, which is a wood typical of the Northern hemisphere [3] [5] [6].

Among the several types of native Brazilian wood species, a species that has been studied with respect to the aging of cachaça is amburana (Amburana cearensis), which belongs to the Leguminoseae Papilonoideae (Fabaceae) family and is commonly known as amburana, imburana-de-cheiro and cumaru [7]. Although it is considered to be a native of the northeastern backlands, the occurrence of $A$. cearenses may be observed in nearly all of South America (from Peru to Argentina). It is a leafy tree that may attain a height of $15 \mathrm{~m}$, with white flowers, flattened pod and brownish-red bark. It has a pleasant odor that is conferred by the presence of coumarins [8].

The main reactions that occur during the aging process are reactions among secondary compounds obtained from distillation, direct extraction of wood components, decomposition of the wood macromolecules (cellulose, hemicellulose and lignin) and the subsequent incorporation of these compounds into the beverage. Furthermore, reactions may occur among the wood compounds and the original compounds of the distilled beverage [9] [10].

The main compounds extracted from wood by the distillates are volatile oils, phenolic compounds, tannic substances, sugars, glycerol and non-volatile organic acids. Among them, the importance of studying phenolic compounds in aged cachaças because of the value of antioxidant compounds for human health should be highlighted [11] [12].

Several studies have assessed the chemical and sensorial quality of aged beverages. Many aldehydes and phenolic acids have been found in distilled alcoholic beverages aged in oak barrels, such as vanillin, syringaldehyde, coniferaldehyde and sinapaldehyde, which were apparently formed by the acid alcoholysis of lignin. Other phenolic acids that have been identified are gallic acid, $p$-hydroxybenzoic acid, $p$-coumaric acid, cinnamic acid, vanillic acid and syringic acid [13].

High-performance liquid chromatography with UV-Vis detectors is widely cited in the literature for the detection of phenolic compounds in beverages [14]-[17]. In addition to HPLC, other techniques are used, such as gas chromatography, capillary electrophoresis (CE), ultraviolet detection, electrochemistry, and fluorescent and mass spectrometries [18]. This work sought to compare the development of 12 phenolic compounds in cachaças aged during a period of 12 months in oak (Quercus sp) and amburana (Amburana cearensis) barrels using HPLC with UV-Vis detection.

\section{Material and Methods}

\subsection{Sample Collection}

The samples were produced in a commercial alembic located in the municipality of Perdões, Minas Gerais, Brazil during the harvest of 2011. Distillation was performed in a copper alembic. The cachaça was aged in oak (Quercus sp) and amburana (Amburana cearensis) barrels, both having a capacity of $200 \mathrm{~L}$, and $130 \mathrm{~L}$ of beverage was stored in each barrel. The barrels were kept in closed sheds with controlled temperature and air humidity. They were positioned horizontally to provide a greater contact between the beverage and the wood, and the barrels were distanced from one another to avoid gas exchange. Two-liter aliquots were collected each month during 12 months and sent for the analyses of phenolic compounds. The analyses were performed at the Laboratório de Qualidade de Aguardentes, Departamento de Química (DQI), Universidade Federal de Lavras (UFLA).

\subsection{Chromatographic Analysis}

Chromatographic analyses were performed on a Shimadzu HPLC equipped with two model SPD-M20A high- 
pressure pumps, a model DGU-20A3 degasser, a model CBM-20A interface, a model SIL-10AF automatic injector and a diode array detector (DAD). The column employed was an Agilent-Zorbax Eclipse XDB-C18 (4.6 × $250 \mathrm{~mm}, 5 \mu \mathrm{m})$ connected to an Agilent-Zorbax Eclipse XDB-C18 4-Pack (4.6 × $12.5 \mathrm{~mm}, 5 \mu \mathrm{m})$ pre-column.

The 12 phenolic compounds in cachaças aged in oak and amburana barrels were analyzed according to the method proposed by Anjos [2]. The phenolic compounds were gallic acid, catechin, vanillic acid, phenol, syringic acid, vanillin, syringaldehyde, $p$-coumaric acid, sinapic acid, coumarin, 4-methylumbelliferone and $o$-coumaric acid. The standards for these compounds were acquired from Sigma-Aldrich or Acros Organics. The solvents employed in the mobile phase were HPLC grade: methanol (Merck) and glacial acetic acid (J. T. Baker) and water type I obtained from a Milli-Q system.

External standardization was used for quantification. To construct the analytical curves, dilutions were performed with an intermediate solution containing a mixture of all the standards, which was obtained by means of the dilution of previously prepared stock solutions. This intermediate solution contained the following concentrations of the standards: gallic acid $\left(6.80 \mathrm{mg} \cdot \mathrm{L}^{-1}\right)$, catechin $\left(11.61 \mathrm{mg} \cdot \mathrm{L}^{-1}\right)$, vanillic acid $\left(6.73 \mathrm{mg} \cdot \mathrm{L}^{-1}\right)$, phenol $\left(3.76 \mathrm{mg} \cdot \mathrm{L}^{-1}\right)$, syringic acid $\left(7.93 \mathrm{mg} \cdot \mathrm{L}^{-1}\right)$, vanillin $\left(6.08 \mathrm{mg} \cdot \mathrm{L}^{-1}\right)$, syringaldehyde $\left(7.29 \mathrm{mg} \cdot \mathrm{L}^{-1}\right), p$-coumaric acid $\left(6.56 \mathrm{mg} \cdot \mathrm{L}^{-1}\right)$, sinapic acid $\left(8.97 \mathrm{mg} \cdot \mathrm{L}^{-1}\right)$, coumarin $\left(5.85 \mathrm{mg} \cdot \mathrm{L}^{-1}\right)$, 4-methylumbelliferone $\left(7.05 \mathrm{mg} \cdot \mathrm{L}^{-1}\right)$ and $o$-coumaric acid $\left(6.56 \mathrm{mg} \cdot \mathrm{L}^{-1}\right)$.

The solutions of $2 \%$ acetic acid in water (Solvent A) and methanol: water: acetic acid (70:28:2\% v/v) (Solvent B) were used as the mobile phase for eluting the compounds. Samples and standards were eluted using the following gradients: from 0 to $25 \min (0 \%$ - 40\% B); 25 - $40 \min (40 \%$ - 55\% B); 40 - 50 min (55\% - 100\% B); 50 $60 \mathrm{~min}(100 \%-0 \% \mathrm{~B})$. The wavelength employed was $280 \mathrm{~nm}$, the flow rate was $0.8 \mathrm{mg} \cdot \mathrm{L}^{-1}$, and the volume injected was $20 \mu \mathrm{L}$.

Samples and standards were filtered through a $0.45-\mu \mathrm{m}$ polyethylene membrane (Millipore) and injected directly into the chromatographic system. Injections of standards and samples were performed in triplicates. The identities of the analytes were confirmed using the retention times, and the profiles of sample peaks were compared with those of the standards.

To guarantee the analytical quality of the results, procedures were performed to validate the method, which was assessed according to the following parameters: selectivity, linearity, limit of detection, limit of quantification and accuracy [2]-[19]. The selectivity was determined through the use of a fresh cachaça (without contact with wood). Initially, an analysis of this cachaça, to which the standards were added, was performed. The mathematical relationship between the sign and the concentration of the species of interest was expressed by means of the line equations (analytical curves) and their respective determination coefficients $\left(\mathrm{R}^{2}\right)$.

The limits of detection and quantification of the methods were estimated using the parameters of the analytical curve according to the mathematical equations: $\mathrm{LD}=3 \times(\mathrm{s} / \mathrm{S})$ and $\mathrm{LQ}=10 \times(\mathrm{s} / \mathrm{S})$, in which $\mathrm{s}$ is the estimate of the standard deviation of the equation for the regression line, and $S$ is the angular coefficient of the analytical curve. The accuracy was assessed by means of recovery assays using three randomly chosen samples that were fortified with analyte standards at three different concentrations. The recovery was determined by considering the results obtained for each analyte using the following mathematical equation: \%Recovery $=[$ (measured concentration)/(expected concentration) $] \times 100$ [19].

\subsection{Statistical Analysis}

A completely randomized design (CRD) was used in a scheme of fractions subdivided in the space. The data were submitted to analysis of variance, and the means were compared by the Scott-Knott test at $95 \%$ of confidence using the statistical software SISVAR [20]. A principal component analysis (PCA) was performed to verify possible similarities between the types of wood with respect to the concentrations of phenolic compounds. Results were centered on the mean for posterior analysis, which was accomplished using the CHEMOFACE software [21].

\section{Results and Discussion}

The chromatogram of the standard solution of the 12 phenolic compounds obtained through spectrophotometric detection after analysis of $20 \mu \mathrm{L}$ by HPLC is presented in Figure 1. The compounds were well separated under the chromatographic conditions employed.

The mean retention time observed for each compound was: 1) gallic acid (8.754 $\pm 0.433 \mathrm{~min})$; 2) catechin 


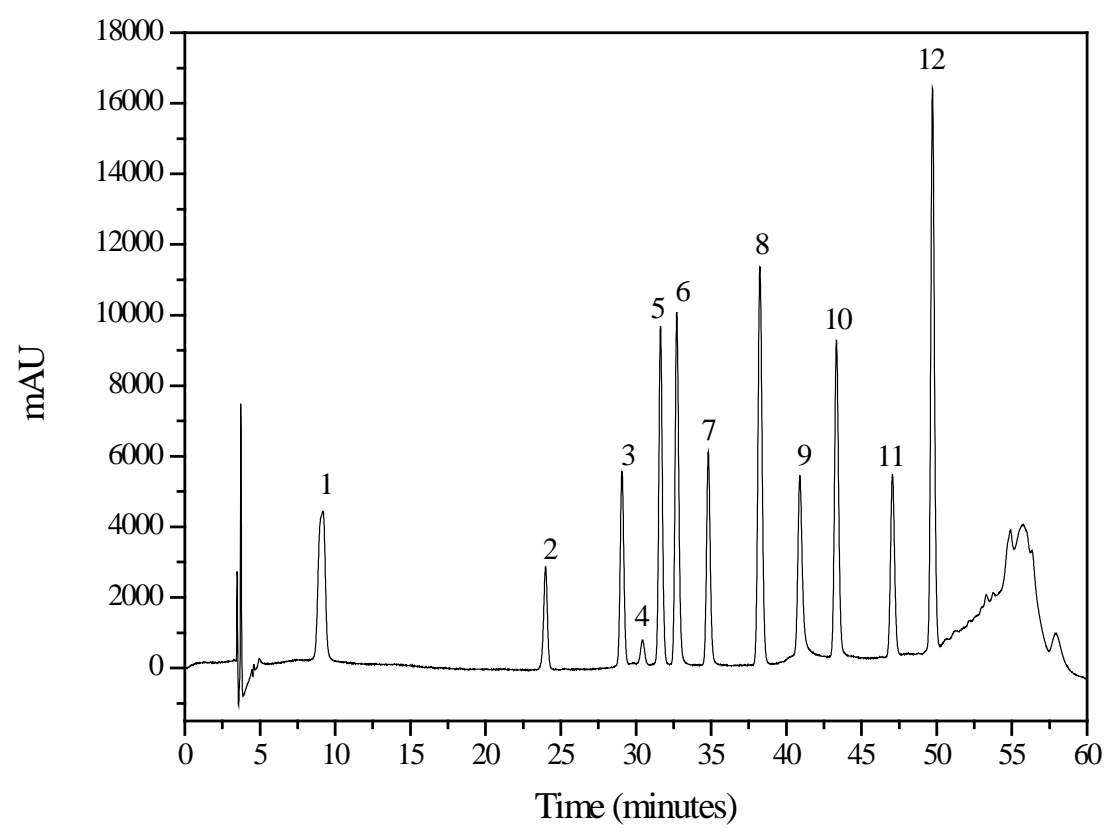

Figure 1. Chromatogram of the standard solution of phenolic compounds with spectrophotometric detection. Concentration of each standard: $1.161 \times 10^{-5} \mathrm{mg} \cdot \mathrm{L}^{-1}$.

(23.961 $\pm 0.107 \mathrm{~min}) ; 3)$ vanillic acid (29.021 $\pm 0.119 \mathrm{~min})$; 4) phenol (29.607 $\pm 0.457 \mathrm{~min})$; 5) syringic acid (31.571 $\pm 0.105 \mathrm{~min}) ; 6)$ vanillin (32.647 $\pm 0.104 \mathrm{~min})$; 7) syringaldehyde (34.721 $\pm 0.135 \mathrm{~min}) ; 8) p$-coumaric acid (38.085 $\pm 0.349 \mathrm{~min}) ; 9)$ sinapic acid (40.743 $\pm 0.212 \mathrm{~min}) ; 10)$ coumarin (42.294 $\pm 0.962 \mathrm{~min})$; 11) 4-methylumbelliferone (46.843 $\pm 0.126 \mathrm{~min}$ ); and 12) o-coumaric acid (49.501 $\pm 0.128 \mathrm{~min}$ ), values that corroborate with those found by Anjos [2]. In the end of the run, an increase was observed in the base line that may be explained by the presence of oligomers and polymers. In the literature, studies that correlate the phenol contents with the use of reversed-phase liquid chromatography relate that the presence of many oligomers and polymers of flavan-3-ol results in alterations in the base line of the chromatograms [22] [23].

The selectivity of the methods employed was assessed through the comparison between the matrix lacking the substances of interest (phenolic compounds) and the matrix with the analyte standards (Figure 2). A positive selectivity was observed, because the chromatogram presented a satisfactory separation of the compounds.

The correlation coefficients ranged from 0.9994 to 0.9999 , thus showing a strong linear correlation between the concentrations of the analyzed compounds and the area of the peaks, as recommended in the literature [24] [25]. The correlation coefficients, limits of detection and limits of quantification obtained are presented on Table 1.

The limits of detection and quantification found for the phenolic compounds ranged from 0.025 to 0.057 $\mathrm{mg} \cdot \mathrm{L}^{-1}$ and from 0.084 to $0.190 \mathrm{mg} \cdot \mathrm{L}^{-1}$, respectively. These values were inferior to those found by Aquino and Santiago [6]-[17], and were close to those obtained by Anjos and Zacaroni [2]-[13]. Anjos [2] found values between 0.016 and $0.131 \mathrm{mg} \cdot \mathrm{L}^{-1}$ and ranging from 0.055 to $0.437 \mathrm{mg} \cdot \mathrm{L}^{-1}$ for the limits of detection and quantification, respectively. Santiago [17] found limits of detection and quantification ranging from 0.031 to 0.168 $\mathrm{mg} \cdot \mathrm{L}^{-1}$ and 0.104 to $0.677 \mathrm{mg} \cdot \mathrm{L}^{-1}$, respectively.

The method employed for the analysis of phenolic compounds in cachaça aged in wood barrels was shown to be highly sensitive. The differences may be explained by differences in chromatographic conditions, such as the equipment and/or methods adopted for quantifying the compounds [19]-[26].

The accuracy of the analytical method was assessed by means of recovery assays in which the concentration of phenolic compounds was calculated through the increase of peak areas obtained after the addition of a known amount of standard to three randomly chosen samples [2]. The mean results for the percentage of recovery were 92\% for gallic acid, $82 \%$ for catechin, $95 \%$ for vanillic acid, $90 \%$ for phenol, $92 \%$ for syringic acid, $96 \%$ for vanillin, $93 \%$ for syringaldehyde, $94 \%$ for $p$-coumaric acid, 91\% for sinapic acid, $95 \%$ for coumarin, $96 \%$ for 4-methylumbelliferone and $86 \%$ for $o$-coumaric acid. 


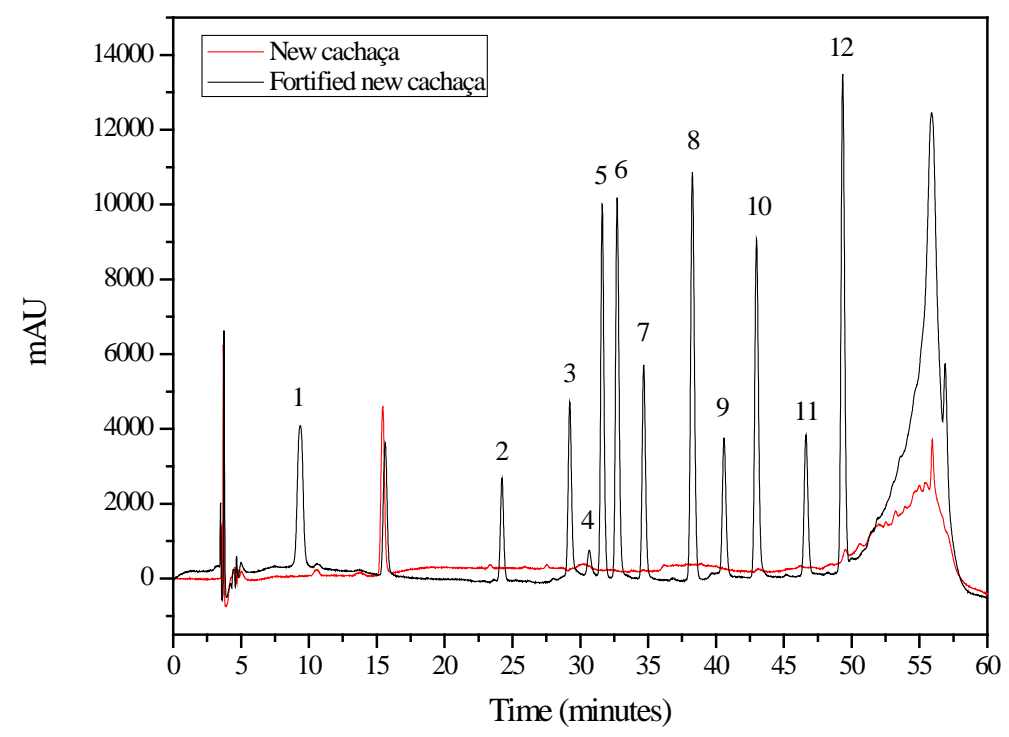

Figure 2. Chromatogram of the fresh cachaça and that fortified with standards of phenolic compounds at the $1.04 \times 10^{-5} \mathrm{~mol} \cdot \mathrm{L}^{-1}$ concentration. Identification of peaks: (1) gallic acid; (2) catechin; (3) vanillic acid; (4) phenol; (5) syringic acid; (6) vanillin; (7) syringaldehyde; (8) p-coumaric acid; (9) sinapic acid; (10) coumarin; (11) 4-methylumbelliferone; and (12) $o$-coumaric acid.

Table 1. Parameters, correlation coefficients $\left(\mathrm{r}^{2}\right)$ for the analytical curves, and limits of detection (LD) and quantification (LQ)* obtained by the analytical method employed.

\begin{tabular}{cccccc}
\hline Compound & $\mathrm{b}$ & $\mathrm{a}$ & $\mathrm{r}^{2}$ & $\mathrm{LD}\left(\mathrm{mg} \cdot \mathrm{L}^{-1}\right)$ & $\mathrm{LQ}\left(\mathrm{mg} \cdot \mathrm{L}^{-1}\right)$ \\
\hline Gallic acid & 68463.23 & -3035.01 & 0.9998 & 0.044 & 0.146 \\
Catechin & 16893.41 & -671.57 & 0.9999 & 0.057 & 0.190 \\
Vanillic acid & 44512.01 & -1041.40 & 0.9995 & 0.035 & 0.116 \\
Phenol & 12042.23 & -403.83 & 0.9994 & 0.032 & 0.107 \\
Syringic acid & 74757.71 & -1607.86 & 0.9997 & 0.035 & 0.117 \\
Vanillin & 96068.54 & -2649.16 & 0.9996 & 0.027 & 0.091 \\
Syringaldehyde & 49814.62 & -2113.48 & 0.9998 & 0.034 & 0.116 \\
-Coumaric acid & 116451.88 & -1282.22 & 0.9994 & 0.025 & 0.084 \\
Sinapic acid & 31456.89 & -2638.53 & 0.9996 & 0.046 & 0.155 \\
Coumarin & 108863.21 & -2863.04 & 0.9998 & 0.026 & 0.087 \\
4-Methylumbelliferone & 32840.07 & 1089.44 & 0.9996 & 0.043 & 0.147 \\
o-Coumaric acid & 149391.38 & -3430.66 & 0.9997 & 0.033 & 0.113
\end{tabular}

* Linear regression: $\mathrm{y}=\mathrm{bx}+\mathrm{a}$.

According to Ribani and Collins [19]-[26], the acceptable values of recovery for analyses are between 70 and $120 \%$, with an accuracy of $\pm 20 \%$. However, depending on the analytical complexity of the sample, this value may vary from $50 \%$ to $120 \%$, with an accuracy of $\pm 15 \%$. Thus, according to the results found in the present work for the 12 phenolic compounds studied, the method presented a high recovery, with the mean values ranging from $82 \%$ to $96 \%$. There are studies in the literature reporting recoveries close to those observed in the current work [2]-[13]. The results obtained for the quantification of 12 phenolic compounds during the aging of cachaça in oak and amburana barrels are presented on Table 2 and Table 3, respectively. 
Table 2. Concentrations of 12 phenolic compounds $\left(\mathrm{mg} \cdot \mathrm{L}^{-1}\right)$ observed during the aging of cachaça in oak barrels.

\begin{tabular}{|c|c|c|c|c|c|c|c|}
\hline Aging time (months) & $\mathbf{0}$ & 1 & 2 & 3 & 4 & 5 & 6 \\
\hline \multicolumn{8}{|l|}{ Compounds } \\
\hline Gallic acid & ND & $0.213 \pm 0.001$ & $0.269 \pm 0.003$ & $0.317 \pm 0.003$ & $0.367 \pm 0.004$ & $0.417 \pm 0.001$ & $0.477 \pm 0.003$ \\
\hline Catechin & ND & $<\mathrm{LQ}$ & $<\mathrm{LQ}$ & $<\mathrm{LQ}$ & $<\mathrm{LQ}$ & $<\mathrm{LQ}$ & $<\mathrm{LQ}$ \\
\hline Vanillic acid & ND & $<\mathrm{LQ}$ & $<\mathrm{LQ}$ & $<\mathrm{LQ}$ & $<\mathrm{LQ}$ & $<\mathrm{LQ}$ & $<\mathrm{LQ}$ \\
\hline Phenol & ND & ND & ND & ND & ND & ND & ND \\
\hline Syringic acid & ND & $<\mathrm{LQ}$ & $<\mathrm{LQ}$ & $0.138 \pm 0.001$ & $0.169 \pm 0.001$ & $0.190 \pm 0.001$ & $0.221 \pm 0.001$ \\
\hline Vanillin & ND & $<\mathrm{LQ}$ & $<\mathrm{LQ}$ & $0.097 \pm 0.001$ & $0.113 \pm 0.001$ & $0.119 \pm 0.006$ & $0.134 \pm 0.002$ \\
\hline Syringaldehyde & ND & $0.118 \pm 0.002$ & $0.135 \pm 0.002$ & $<\mathrm{LQ}$ & $0.177 \pm 0.005$ & $0.210 \pm 0.006$ & $0.231 \pm 0.004$ \\
\hline$p$-Coumaric acid & ND & $<\mathrm{LQ}$ & $<\mathrm{LQ}$ & $<\mathrm{LQ}$ & $<\mathrm{LQ}$ & $<\mathrm{LQ}$ & $<\mathrm{LQ}$ \\
\hline Sinapic acid & ND & $<\mathrm{LQ}$ & $<\mathrm{LQ}$ & $<\mathrm{LQ}$ & $<\mathrm{LQ}$ & $<\mathrm{LQ}$ & $<\mathrm{LQ}$ \\
\hline Coumarin & ND & $<\mathrm{LQ}$ & $<\mathrm{LQ}$ & $<\mathrm{LQ}$ & $<\mathrm{LQ}$ & $<\mathrm{LQ}$ & $<\mathrm{LQ}$ \\
\hline 4-Methylumbelliferone & ND & ND & ND & ND & ND & ND & ND \\
\hline$o$-Coumaric acid & ND & $<\mathrm{LQ}$ & $<\mathrm{LQ}$ & $<\mathrm{LQ}$ & $<\mathrm{LQ}$ & $<\mathrm{LQ}$ & $<\mathrm{LQ}$ \\
\hline $\begin{array}{l}\text { Sum of each } \\
\text { phenolic compound } \\
\text { (on each month) }\end{array}$ & ND & 0.331 & 0.404 & 0.552 & 0.826 & 0.936 & 1.063 \\
\hline
\end{tabular}

\begin{tabular}{|c|c|c|c|c|c|c|c|}
\hline Aging time (months) & 7 & 8 & 9 & 10 & 11 & 12 & $\begin{array}{c}\text { Evolution/ } \\
\text { Times }\end{array}$ \\
\hline \multicolumn{8}{|l|}{ Compounds } \\
\hline Gallic acid & $0.522 \pm 0.004$ & $0.567 \pm 0.001$ & $0.606 \pm 0.001$ & $0.652 \pm 0.007$ & $0.691 \pm 0.003$ & $0.720 \pm 0.003$ & 3.380 \\
\hline Catechin & $<\mathrm{LQ}$ & $<\mathrm{LQ}$ & $<\mathrm{LQ}$ & $<\mathrm{LQ}$ & $<\mathrm{LQ}$ & $<\mathrm{LQ}$ & - \\
\hline Vanillic acid & $<\mathrm{LQ}$ & $<\mathrm{LQ}$ & $<\mathrm{LQ}$ & $<\mathrm{LQ}$ & $<\mathrm{LQ}$ & $<\mathrm{LQ}$ & - \\
\hline Phenol & ND & ND & ND & ND & ND & ND & - \\
\hline Syringic acid & $0.245 \pm 0.001$ & $0.272 \pm 0.003$ & $0.294 \pm 0.001$ & $0.315 \pm 0.001$ & $0.332 \pm 0.001$ & $0.346 \pm 0.009$ & 2.507 \\
\hline Vanillin & $0.142 \pm 0.003$ & $0.153 \pm 0.001$ & $0.158 \pm 0.001$ & $0.174 \pm 0.007$ & $0.194 \pm 0.002$ & $0.201 \pm 0.004$ & 2.072 \\
\hline Syringaldehyde & $0.250 \pm 0.001$ & $0.279 \pm 0.002$ & $0.301 \pm 0.001$ & $0.323 \pm 0.001$ & $0.334 \pm 0.001$ & $0.346 \pm 0.012$ & 2.932 \\
\hline$p$-Coumaric acid & $<\mathrm{LQ}$ & $<\mathrm{LQ}$ & $<\mathrm{LQ}$ & $0.045 \pm 0.003$ & $0.048 \pm 0.009$ & $<\mathrm{LQ}$ & 1.066 \\
\hline Sinapic acid & $<\mathrm{LQ}$ & $<\mathrm{LQ}$ & $<\mathrm{LQ}$ & $0.157 \pm 0.003$ & $0.157 \pm 0.009$ & $0.157 \pm 0.015$ & 1.000 \\
\hline Coumarin & $<\mathrm{LQ}$ & $<\mathrm{LQ}$ & $<\mathrm{LQ}$ & $<\mathrm{LQ}$ & $<\mathrm{LQ}$ & $<\mathrm{LQ}$ & - \\
\hline 4-Methylumbelliferone & ND & ND & ND & ND & ND & ND & - \\
\hline$o$-Coumaric acid & $<\mathrm{LQ}$ & $<\mathrm{LQ}$ & $<\mathrm{LQ}$ & $<\mathrm{LQ}$ & $<\mathrm{LQ}$ & $<\mathrm{LQ}$ & - \\
\hline $\begin{array}{l}\text { Sum of each } \\
\text { phenolic compound } \\
\text { (on each month) }\end{array}$ & 1.159 & 1.271 & 1.359 & 1.666 & 1.747 & 1.770 & - \\
\hline
\end{tabular}

$\mathrm{ND}=$ non-detected; $<\mathrm{LD}=$ lower than the limit of detection; $<\mathrm{LQ}=$ lower than the limit of quantification. 
Table 3. Concentrations of 12 phenolic compounds $\left(\mathrm{mg} \cdot \mathrm{L}^{-1}\right)$ observed during the aging of cachaça in amburana barrels.

\begin{tabular}{|c|c|c|c|c|c|c|c|}
\hline Aging time (months) & $\mathbf{0}$ & 1 & 2 & 3 & 4 & 5 & 6 \\
\hline \multicolumn{8}{|l|}{ Compounds } \\
\hline Gallic acid & ND & $0.326 \pm 0.006$ & $0.405 \pm 0.004$ & $0.510 \pm 0.006$ & $0.646 \pm 0.006$ & $0.829 \pm 0.002$ & $1.007 \pm 0.008$ \\
\hline Catechin & ND & $<\mathrm{LQ}$ & $<\mathrm{LQ}$ & $<\mathrm{LQ}$ & $<\mathrm{LQ}$ & $<\mathrm{LQ}$ & $<\mathrm{LQ}$ \\
\hline Vanillic acid & ND & $1.095 \pm 0.009^{* *}$ & $2.975 \pm 0.006^{* *}$ & $4.089 \pm 0.004^{* *}$ & $4.741 \pm 0.007^{* *}$ & $5.451 \pm 0.050^{* *}$ & $6.101 \pm 0.009^{* *}$ \\
\hline Phenol & ND & $0.112 \pm 0.004$ & $0.226 \pm 0.003$ & $0.255 \pm 0.012$ & $0.333 \pm 0.001$ & $0.389 \pm 0.014$ & $0.451 \pm 0.002$ \\
\hline Syringic acid & ND & $0.869 \pm 0.011$ & $0.789 \pm 0.002$ & $0.790 \pm 0.002$ & $0.846 \pm 0.001$ & $0.921 \pm 0.007$ & $0.988 \pm 0.016$ \\
\hline Vanillin & ND & $0.098 \pm 0.001$ & $0.090 \pm 0.006$ & $0.084 \pm 0.003$ & $0.081 \pm 0.001$ & $0.103 \pm 0.003$ & $0.113 \pm 0.002$ \\
\hline Syringaldehyde & ND & $0.805 \pm 0.004$ & $0.744 \pm 0.002$ & $0.806 \pm 0.005$ & $0.927 \pm 0.005$ & $1.092 \pm 0.002$ & $1.304 \pm 0.006$ \\
\hline$p$-Coumaric acid & ND & $0.119 \pm 0.007$ & $0.147 \pm 0.001$ & $0.166 \pm 0.001$ & $0.183 \pm 0.023$ & $0.350 \pm 0.001$ & $0.393 \pm 0.003$ \\
\hline Sinapic acid & ND & $0.255 \pm 0.001$ & $0.634 \pm 0.004$ & $0.881 \pm 0.003$ & $0.947 \pm 0.052$ & $1.088 \pm 0.015$ & $1.206 \pm 0.040$ \\
\hline Coumarin & ND & $<\mathrm{LQ}$ & $<\mathrm{LQ}$ & $<\mathrm{LQ}$ & $<\mathrm{LQ}$ & $<\mathrm{LQ}$ & $<\mathrm{LQ}$ \\
\hline 4-Methylumbelliferone & ND & $<\mathrm{LQ}$ & $<\mathrm{LQ}$ & $0.254 \pm 0.015$ & $0.334 \pm 0.012$ & $0.503 \pm 0.005$ & $0.511 \pm 0.019$ \\
\hline$o$-Coumaric acid & ND & $<\mathrm{LQ}$ & $0.145 \pm 0.015$ & $0.167 \pm 0.003$ & $0.172 \pm 0.006$ & $0.173 \pm 0.001$ & $0.180 \pm 0.007$ \\
\hline $\begin{array}{c}\text { Sum of each } \\
\text { phenolic compound } \\
\text { (on each month) }\end{array}$ & ND & 3.679 & 6.155 & 8.002 & 9.210 & 10.899 & 12.324 \\
\hline
\end{tabular}

\begin{tabular}{|c|c|c|c|c|c|c|c|}
\hline Aging time (months) & 7 & 8 & 9 & 10 & 11 & 12 & $\begin{array}{c}\text { Evolution/ } \\
\text { Times }\end{array}$ \\
\hline \multicolumn{8}{|l|}{ Compounds } \\
\hline Gallic acid & $1.188 \pm 0.004$ & $1.372 \pm 0.005$ & $1.528 \pm 0.002$ & $1.661 \pm 0.008^{* *}$ & $1.757 \pm 0.002^{* *}$ & $1.865 \pm 0.005^{* *}$ & 5.721 \\
\hline Catechin & $0.209 \pm 0.010$ & $0.217 \pm 0.004$ & $0.231 \pm 0.003$ & $0.229 \pm 0.003$ & $0.230 \pm 0.010$ & $0.244 \pm 0.010$ & 1.167 \\
\hline Vanillic acid & $6.574 \pm 0.046^{* *}$ & $7.111 \pm 0.068^{* *}$ & $7.512 \pm 0.028^{* *}$ & $7.857 \pm 0.023^{* *}$ & $8.023 \pm 0.002^{* *}$ & $8.355 \pm 0.032^{* *}$ & 7.630 \\
\hline Phenol & $0.470 \pm 0.015$ & $0.462 \pm 0.001$ & $0.493 \pm 0.003$ & $0.489 \pm 0.013$ & $0.550 \pm 0.034$ & $0.785 \pm 0.078$ & 7.008 \\
\hline Syringic acid & $1.042 \pm 0.001$ & $1.092 \pm 0.001$ & $1.118 \pm 0.006$ & $1.135 \pm 0.006$ & $1.159 \pm 0.013$ & $1.254 \pm 0.005$ & 1.443 \\
\hline Vanillin & $0.125 \pm 0.002$ & $0.140 \pm 0.005$ & $0.147 \pm 0.001$ & $0.155 \pm 0.001$ & $0.157 \pm 0.001$ & $0.156 \pm 0.004$ & 1.592 \\
\hline Syringaldehyde & $1.490 \pm 0.018$ & $1.667 \pm 0.015$ & $1.799 \pm 0.040$ & $1.957 \pm 0.003^{* *}$ & $2.024 \pm 0.020^{* *}$ & $2.226 \pm 0.002^{* *}$ & 2.765 \\
\hline$p$-Coumaric acid & $0.433 \pm 0.001$ & $0.470 \pm 0.004$ & $0.508 \pm 0.001$ & $0.525 \pm 0.005$ & $0.556 \pm 0.006$ & $0.601 \pm 0.003$ & 5.050 \\
\hline Sinapic acid & $1.262 \pm 0.036$ & $1.384 \pm 0.029$ & $1.498 \pm 0.034$ & $1.806 \pm 0.026$ & $1.761 \pm 0.050$ & $2.577 \pm 0.040^{* *}$ & 10.105 \\
\hline Coumarin & $<\mathrm{LQ}$ & $<\mathrm{LQ}$ & $<\mathrm{LQ}$ & $<\mathrm{LQ}$ & $<\mathrm{LQ}$ & $<\mathrm{LQ}$ & - \\
\hline 4-Methylumbelliferone & $0.707 \pm 0.059$ & $1.076 \pm 0.010$ & $1.263 \pm 0.002$ & $1.363 \pm 0.025$ & $1.566 \pm 0.020$ & $1.727 \pm 0.018$ & 6.799 \\
\hline$o$-Coumaric acid & $0.185 \pm 0.006$ & $0.203 \pm 0.003$ & $0.229 \pm 0.010$ & $0.238 \pm 0.008$ & $0.267 \pm 0.002$ & $0.256 \pm 0.017$ & 1.765 \\
\hline $\begin{array}{c}\text { Sum of each } \\
\text { phenolic compound } \\
\text { (on each month) }\end{array}$ & 13.685 & 15.194 & 16.326 & 17.415 & 18.050 & 20.049 & - \\
\hline
\end{tabular}

$\mathrm{ND}=$ non-detected; $<\mathrm{LD}=$ lower than the limit of detection; $<\mathrm{LQ}=$ lower than the limit of quantification; ${ }^{* *}$ Sample diluted (10 times) in $40 \%$ ethyl alcohol for the quantification. 
A progressive increase in the concentration of phenolic compounds for each species of wood analyzed was observed. The concentration ranged from 0.331 to $1.770 \mathrm{mg} \cdot \mathrm{L}^{-1}$ (for cachaça aged for 1 to 12 months in oak barrels) and from 3.679 to $20.049 \mathrm{mg} \cdot \mathrm{L}^{-1}$ (for cachaça aged for 1 to 12 months in amburana barrels). It was evident that cachaça aged in amburana barrels contained higher concentrations of phenolic compounds. Such high concentrations may be explained by morphological differences, time of use and type of pre-treatment of the barrel [10]-[27].

The cachaça aged in oak barrels contained a predominance of gallic acid, syringic acid and syringaldehyde, results that corroborate those of Anjos and Zacaroni [2]-[13]. The cachaça aged in amburana barrels contained predomnately gallic acid, vanillic acid, syringaldehyde and sinapic acid. This result differs from that of Santiago [17], who assessed cachaça stored in amburana barrels during four months and observed a predominance of catechin, syringaldehyde and 4-methylumbelliferone. Generally, there is a progressive increase in the concentration of phenolic compounds in cachaças stored in different barrels. Despite the complexity of the process, the mechanism of the gradual increase in the content of acids and aldehydes seems to follow the scheme: cinnamic aldehydes (coniferaldehyde and sinapaldeído), benzoic aldehydes (vanillin and syringaldehyde) and benzoic acids (vanillic acid and syringic acid) [2]-[5]. The differences in the composition of phenols were observed in the chromatograms (Figure 3 and Figure 4) of the cachaças aged in oak and amburana barrels.

The PC1 $\times$ PC2 biplot of loadings and scores in which phenolic compounds of aged cachaças were related with the types of wood studied is presented in Figure 5. The PCA showed that it was possible to describe $99.49 \%$ of the data with the first and second principal components, from which $98.61 \%$ of the total variance was described by the first component. According to this analysis, all the samples differed with respect to the phenolic compounds throughout the different months of aging and the type of wood used in the process.

\section{Conclusion}

The chromatographic method proposed for the determination of 12 phenolic compounds presented acceptable values for all the validation parameters analyzed. A progressive increase was observed with respect to the incorporation of phenolic compounds during the aging of cachaça in barrels constructed from both species of wood. The main compounds quantified in the cachaça aged in the oak barrel were gallic acid, syringaldehyde and syringic acid, and those observed in the cachaça aged in the amburana barrel were vanillic acid, syringaldehyde, sinapic acid and gallic acid.

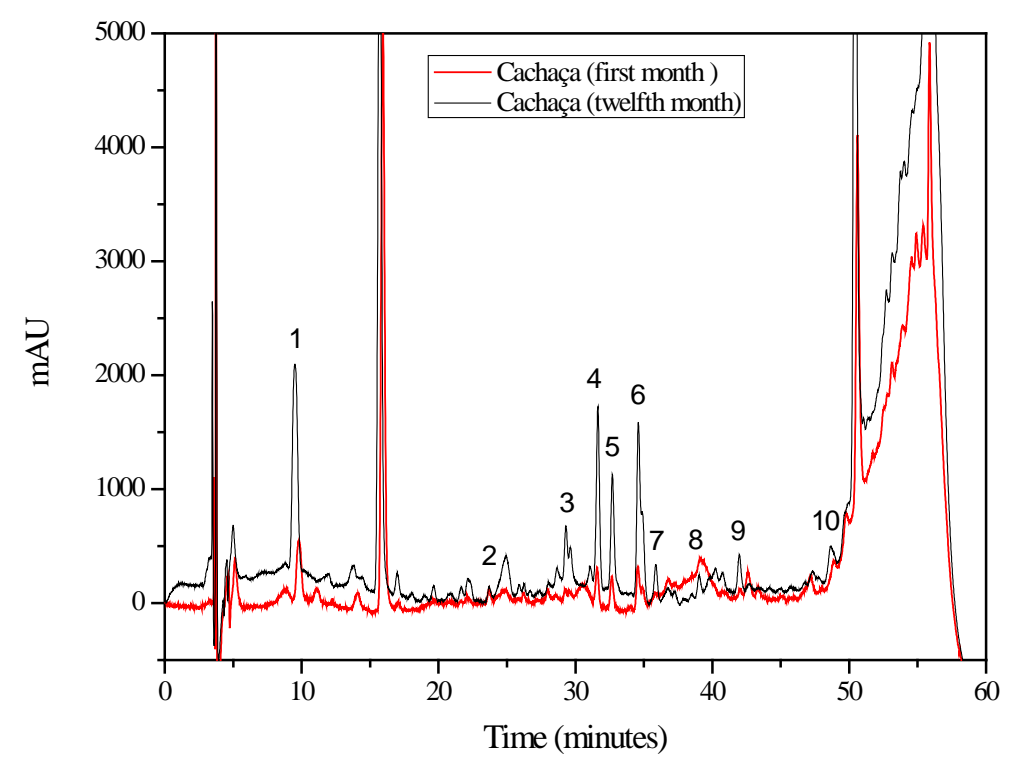

Figure 3. Chromatogram of aged cachaça on the first and twelfth month of storage in oak barrels. Identification of peaks: (1) gallic acid; (2) catechin; (3) vanillic acid; (4) syringic acid; (5) vanillin; (6) syringaldehyde; (7) p-coumaric acid; (8) sinapic acid; (9) coumarin; (10) o-coumaric acid. 


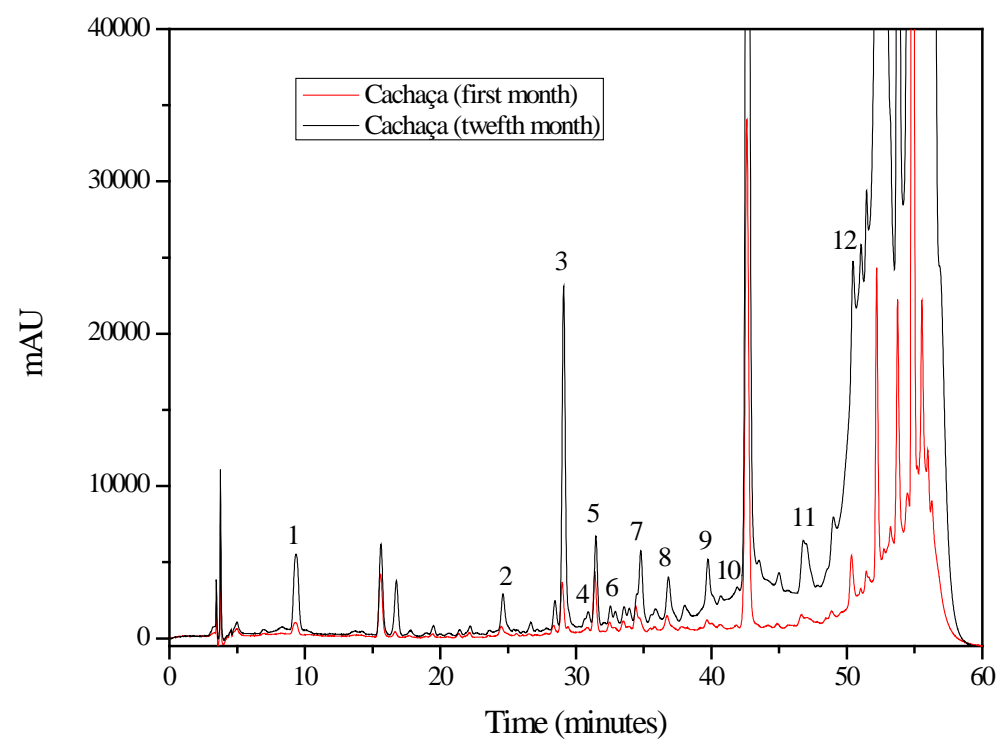

Figure 4. Chromatogram of aged cachaça on the first and twelfth month of storage in amburana barrels. Identification of peaks: (1) gallic acid; (2) catechin; (3) vanillic acid; (4) phenol; (5) syringic acid; (6) vanillin; (7) syringaldehyde; (8) p-coumaric acid; (9) acid sinapic; (10) coumarin; (11) 4-methylumbelliferone; (12) o-coumaric acid.

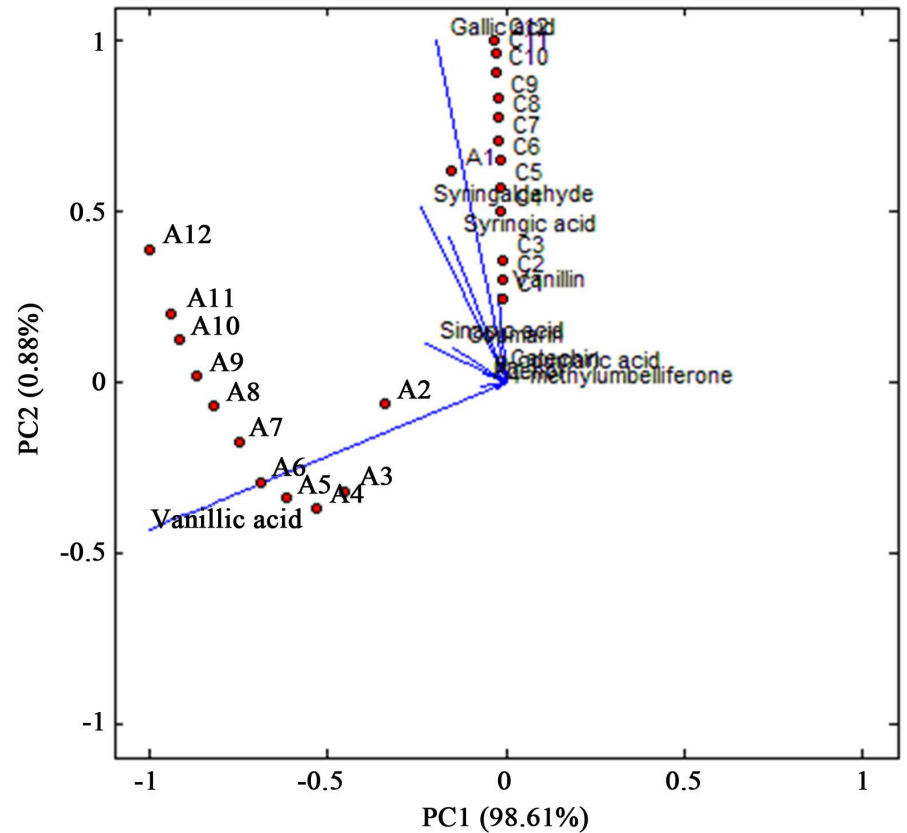

Figure 5. PC1 $\times$ PC2 biplot of loadings and scores of cachaças aged in oak and amburana barrels withs respect to the composition of phenolic compounds.

\section{Acknowledgements}

The authors thank the Conselho Nacional de Desenvolvimento Científico e Tecnológico (CNPQ), the Fundação de Amparo à Pesquisa do Estado de Minas Gerais (FAPEMIG), and the Coordenação de Aperfeiçoamento de Pessoal de Nível Superior (CAPES) for financial support. We also thank Cachaça João Mendes for the valuable contribution and for furnishing the cachaça samples. 


\section{References}

[1] Dias, S.M.B.C., Maia, A.B.R.A. and Nelson, D.L. (2009) Utilização de Madeiras Nativas no Envelhecimento da Cachaça de Alambique. Informe Agropecuário, 30, 49-54.

[2] Anjos, J.P., Cardoso, M.G., Saczk, A.A., Dorea, H.S., Santiago, W.D., Zacaroni, L.M., Machado, A.M.R. and Nelson, D.L. (2011) Evolution of the Concentration of Phenolic Compounds in Cachaça during Aging in an Oak (Quercus sp.) Barrel. Journal of the Brazilian Chemical Society, 22, 1307-1314. http://dx.doi.org/10.1590/S0103-50532011000700016

[3] Aquino, F.W.B., Nascimento, R.F., Rodrigues, S. and Casemiro, A.R.S. (2006) Determinação de Marcadores de Envelhecimento em Cachaças. Ciência e Tecnologia de Alimentos, 26, 145-149. http://dx.doi.org/10.1590/S0101-20612006000100024

[4] Mori, F.A., Mendes, L.M. and Mori, C.L.S.O. (2013) Influência da Madeira no Envelhecimento da Cachaça. In: Cardoso, M.G., Ed., Produção de Aguardente de Cana, Editora UFLA, Lavras, 204-219.

[5] Dias, S., Maia, A. and Nelson, D. (1998) Efeito de Diferentes Madeiras Sobre a Composição da Aguardente de Cana Envelhecida. Ciência e Tecnologia de Alimentos, 18, 3. http://dx.doi.org/10.1590/S0101-20611998000300014

[6] Aquino, F.W.B., Rodrigues, S., Nascimento, R.F. and Casemiro, A.R.S. (2006) Simultaneous Determination of Agind Markers in Sugar Cane Spirits. Food Chemistry, 98, 569-574. http://dx.doi.org/10.1016/j.foodchem.2005.07.034

[7] Maia, G.N. (2004) Caatinga: Árvores e Arbustos e Suas Utilidades. D \& Z Ed, São Paulo.

[8] Canuto, K.M. and Silveira, E.R. (2006) Constituintes Químicos da Casca do Caule de Amburana cearensis A.C. Smith. Química Nova, 29, 1241-1243. http://dx.doi.org/10.1590/S0100-40422006000600018

[9] Sherev, R.N. and Brink, J.A. (1980) Indústria de Fermentação. In: Sherev, R.N., Ed., Indústrias de Processos Químicos, Guanabara Dois, Rio de Janeiro, 469-495.

[10] Cardoso, M.G. (2013) Produção de Aguardente de Cana. 3rd Edition, Editora UFLA, Lavras.

[11] Cardello, H.M.A.B. and Faria, J.B. (2000) Análise da Aceitação de Aguardentes de Cana por Testes Afetivos e Mapa de Preferência Interno. Ciência e Tecnologia de Alimentos, 20, 1. http://dx.doi.org/10.1590/S0101-20612000000100007

[12] Rakić, S., Petrović, S., Kukić, J., Jadranin, M., Tešević, V., Povrenović, D. and Šiler-Marinković, S. (2007) Influence of Thermal Treatment on Phenolic Compounds and Antioxidant Properties of Oak Acorns from Serbia. Food Chemistry, 104, 830-834. http://dx.doi.org/10.1016/j.foodchem.2007.01.025

[13] Zacaroni, L.M., Cardoso, M.G., Saczk, A.A., Morais, A.R., Anjos, J.P., Machado, A.M.R. and Nelson, D.L. (2011) Determination of Phenolic Compounds and Coumarins in Sugar Cane Spirit Aged in Different Species of Wood. Analytical Letters, 44, 2061-2073. http://dx.doi.org/10.1080/00032719.2010.546017

[14] Goldeberg, D.M., Hoffman, B., Yang, J. and Soleas, G.J. (1999) Phenolic Constituents, Furans, and Total Antioxidants Status of Distilled Spirits. Journal of Agriculture Food Chemistry, 47, 3978-3985. http://dx.doi.org/10.1021/jf9811626

[15] Faria, J.B., Cardello, H.M.A.B., Boscolo, M., Isique, W.D., Odello, L. and Franco, D.W. (2003) Evaluation of Brazilian Woods as an Alternative to Oak for Cachaças Aging. European Food Research and Technology, 218, 83-87. http://dx.doi.org/10.1007/s00217-003-0795-Z

[16] Morales, M.L., Benitiz, B. and Troncoso, A.M. (2004) Acellerated of Wine Vinegars with Oak Chips: Evaluation of Wood Flavour Compounds. Food Chemistry, 88, 305-315. http://dx.doi.org/10.1016/j.foodchem.2004.04.004

[17] Santiago, W.D., Cardoso, M.G., Zacaroni, L.M., Anjos, J.P., Machado, A.M.R. and Mendonça, J.G.P. (2012) Perfil Físico-Químico e Quantificação de Compostos Fenólicos e Acroleína em Aguardentes de Cana-de-Açúcar Armazenadas em Tonéis de Diferentes Madeiras. Científica, 40, 189-197.

[18] Gruz, J., Novák, O. and Strnad, M. (2008) Rapid Analysis of Phenolic Acids in Beverages by UPLC-MS/MS. Food Chemistry, 111, 789-794. http://dx.doi.org/10.1016/j.foodchem.2008.05.014

[19] Ribani, M., Bottoli, C.B.G., Collins, C.H., Jardim, I.C.S.F. and Melo, L.F.C. (2004) Validação em Métodos Cromatográficos e Eletroforéticos. Química Nova, 27, 771-780. http://dx.doi.org/10.1590/S0100-40422004000500017

[20] Ferreira, D.F. (2011) SISVAR: A Computer Statistical Analysis System. Ciência e Agrotecnologia, 35, $1039-1042$. http://dx.doi.org/10.1590/S1413-70542011000600001

[21] Nunes, C.A., Freitas, M.P., Pinheiro, A.C.M. and Bastos, S.C. (2012) Chemoface: A Novel Free User-Friendly Interface for Chemometrics. Journal of the Brazilian Chemical Society, 23, 2003-2010. http://dx.doi.org/10.1590/S0103-50532012005000073

[22] Kameyama, M.O., Yanagida, A., Kanda, T. and Nagata, T. (1997) Identification of Catechin Oligomers from Apple (Malus pumila cv. Fuji) in Matrix-Assisted Laser Desorption/Ionization Time-of-Flight Mass Spectrometry and FastAtom Bombardment Mass Spectrometry. Mass Spectrometry, 11, 31-36. 
[23] Quideau, S., Joudes, M., Lefeuvre, D., Moutandon, D., Saucier, C., Glories, Y., Pardon, P. and Pouquier, P. (2005) The Chemistry of Wine Polyphenolic C-Glycosidic Ellagitannins Targeting Human Topoisomerase II. Chemistry: A European Journal, 11, 6503-6513. http://dx.doi.org/10.1002/chem.200500428

[24] Snyder, L.R., Kirkland, J.J. and Glajch, J.L. (1997) Practical HPLC Method Development. 2nd Edition, J. Wiley, New York.

[25] Harris, D.C. (2008) Análise Química Quantitativa. 7th Edition, LTC, Rio de Janeiro.

[26] Collins, C.H., Braga, G.L. and Bonato, P.S. (2007) Fundamentos de Cromatografia. Editora Unicamp.

[27] de Miranda, M.B., Horii, J. and Alcarde, A.R. (2006) Estudo do Efeito da Irradiação Gamma (60Co) na Qualidade da Cachaça e no Tonel de Envelhecimento. Ciência e Tecnologia de Alimentos, 26, 4.

http://dx.doi.org/10.1590/S0101-20612006000400010 
Scientific Research Publishing (SCIRP) is one of the largest Open Access journal publishers. It is currently publishing more than 200 open access, online, peer-reviewed journals covering a wide range of academic disciplines. SCIRP serves the worldwide academic communities and contributes to the progress and application of science with its publication.

Other selected journals from SCIRP are listed as below. Submit your manuscript to us via either submit@scirp.org or Online Submission Portal.
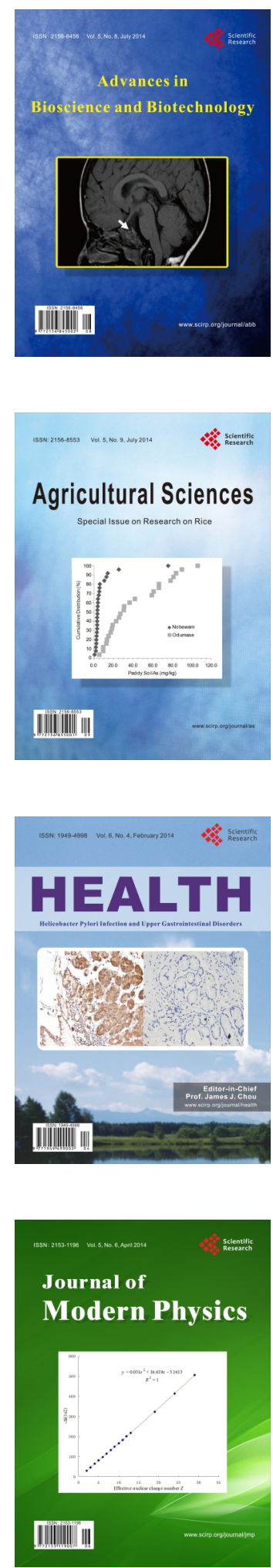
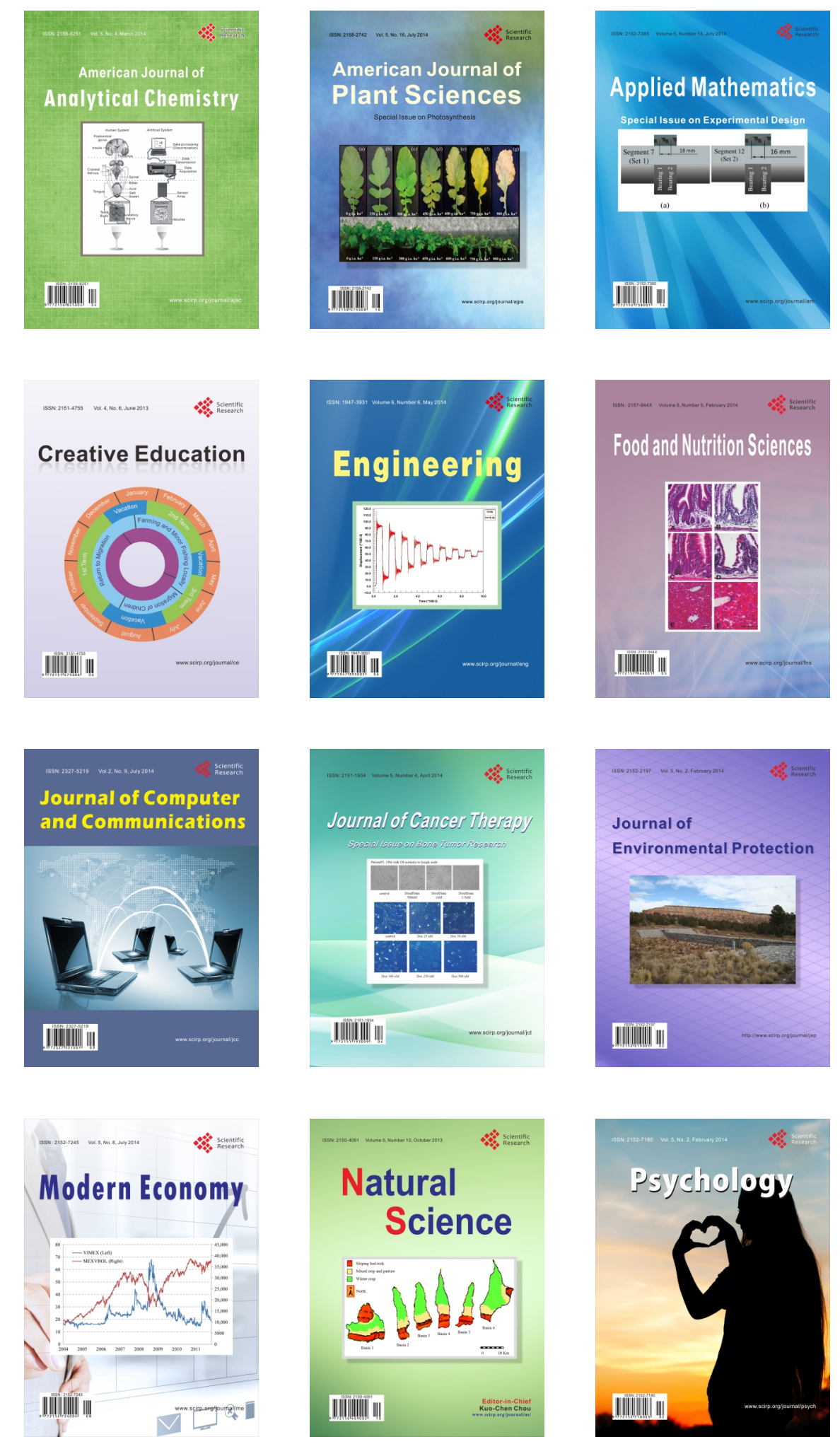